\title{
Refletindo sobre avaliação acadêmica do livro do século XXI
}

\author{
Reflections on the academic evaluation of books in the $21^{\text {st }}$ century \\ Reflexionando sobre la evaluación académica del libro del siglo XXI
}

Flavia Goullart Mota Garcia Rosa ${ }^{1}$

O texto de José Castilho Marques Neto levanta, de forma bastante clara e objetiva, as principais questões que estão no cerne da avaliação dos programas de pós-graduação no que diz respeito ao item livro, quais sejam: como avaliar e gerenciar conteúdos; a ampliação do conceito de livro perante as novas tecnologias; as novas formas de difusão do conhecimento e a adoção de novas tecnologias e, conseqüentemente, de novas formas de difusão do conhecimento com vistas à inclusão social.

Desde a Idade Média, o surgimento das universidades e o aparecimento de um público leitor motivou uma demanda de manuscritos que no século XV, com a criação do processo tipográfico por Gutenberg, ampliou o acesso à informação graças a essa nova tecnologia. Desse modo, fica patente que a história do livro está intimamente ligada ao meio acadêmico, seja para suprir às necessidades de acesso a novos conhecimentos, seja para que os professores/pesquisadores divulguem suas pesquisas. Esses, até os dias de hoje, são os motivadores para que as universidades continuem publicando.

Embora a indústria editorial brasileira tenha se desenvolvido sem estar atrelada ao aparecimento das universidades e, diferentemente da Europa, essa atividade só se inicia no século XIX com a chegada dos primeiros equipamentos de impressão em 1808, graças à vinda da família real, as editoras universitárias têm desempenhado um importante papel no cenário nacional, sobretudo a partir da década de 1980, quando um significativo número de universidades brasileiras começou a se preocupar com a difusão do conhecimento por elas produzido. Elaboram-se políticas para o funcionamento e otimização da produção deste setor acadêmico, de modo a diferenciá-lo das funções exercidas pelas "gráficas universitárias", como eram vistas até então. Grande parte das editoras universitárias passaram a ser respaldadas por conselhos editoriais que, atuantes, buscaram critérios para avaliar a qualidade do conteúdo dos originais a serem publicados. Esse é um dos pontos de destaque do texto de Castilho e, de fato, é um ponto marcante e diferencial no que se refere aos critérios usados pelas editoras vinculadas às universidades.

A sociedade da informação requer que o conhecimento assuma papéis estratégicos, criando novas necessidades e exigindo posturas diferentes dos que são responsáveis pela formação e transmissão do conhecimento. Essa mesma sociedade nos leva a refletir em favor do livre acesso à informação. Reforçando o ponto de vista de Castilho, não podemos

${ }_{1}^{1}$ Professora de Desenho Industrial, Escola de Belas Artes/UFBA; Diretora da Editora da Universidade Federal da Bahia; vice-presidente da Associação Brasileira de Editoras Universitárias (ABEU). <flaviagr@ufba.br>; <flaviagoulartgr@yahoo.com.br>

Rua Barão de Geremoabo, s/no

Campus Universitário

Ondina - Salvador, Ba

40.170-290 
pensar no livro apenas na sua forma tradicional mas, de maneira bem mais ampla, precisamos agregar novas formas de difusão da pesquisa e da informação, possibilitadas pelas novas tecnologias da informação e comunicação (TIC). Segundo Guedes (1998 p.37), a informação

[...] se impõe como a mais poderosa força de transformação do homem, aliando-se aos modernos meios de comunicação para conduzir o desenvolvimento científico e tecnológico das nações, por meio da tão propalada transferência de informação ou difusão de novas idéias e tecnologias. [...] A informação, além do seu aspecto democratizante, exerce papel educativo que concorre para mudanças de significação social e cultural.

É necessário tirar proveito dessas novas possibilidades com o objetivo de construir uma sociedade mais justa e mais democrática. Os periódicos científicos têm avançando muito nesse sentido. O próprio Instituto Brasileiro de Informação em Ciência e Tecnologia (IBICT) lançou o Sistema Eletrônico de Editoração de Revistas - SEER - que é um software livre "desenvolvido para a construção e gerenciamento de todas as etapas de editoração de uma publicação periódica eletrônica, cuja finalidade é otimizar o processo editorial e uma melhor usabilidade e legibilidade da revista" (Meirelles, 2005)

Retomando a questão principal do texto, ou seja, a avaliação acadêmica do livro, entendo-a como uma questão a ser amplamente debatida. $\mathrm{O}$ critério de qualidade do conteúdo que seria o primeiro ponto considerado, precisa ser muito bem auditado, para que não ocorram avaliações subjetivas ou até mesmo discriminatórias, impostas inclusive pela tradição da indústria editorial brasileira, que concentra nas regiões sul e sudeste um maior número de editoras universitárias, tendo, inclusive, uma indústria gráfica mais bem equipada tecnologicamente para atender à especificidade da produção de livros.Outro ponto a ser considerado é como avaliar a questão da tiragem, uma vez que a própria tecnologia permite a impressão por demanda, possibilitando que editoras de menor porte possam participar do mercado editorial, definindo-se por tiragens compatíveis com seu fôlego e sua realidade.

A solução das questões levantadas virá a partir da maturidade das discussões e reflexões. Não basta pensar apenas na universidade como a grande produtora do conhecimento científico, pois "o mercado universitário é não só mais aberto, mas também, mais complexo do que os outros em termos de comunicação das pesquisas" (Meadows, 1999, p.8).

\section{Referências}

GUEDES, M.G. T. M. Comunicação científica: o artigo de periódico nas atividades de ensino e pesquisa do docente universitário brasileiro na pós-graduação. 1998. Tese (Doutorado em Ciência da Informação) Faculdade de Estudos Sociais Aplicados, Universidade de Brasília.

KATZEINSTEIN, U. E. A origem do livro: da idade da pedra ao advento da imprensa no ocidente. São Paulo: Hucitec, 1986.

MEADOWS, A. J. A comunicação científica. Brasília: Briquet de Lemos/Livros, 1999.

MEIRELLES, R. F. Implementação da Revista Brasileira de Saúde e Produção Animal no Sistema Eletrônico de Editoração de Revistas - SEER. In: CINFORM - ENCONTRO NACIONAL DE CIÊNCIA DA INFORMAÇÃO, 6., 2005, Salvador. Anais eletrônicos... Salvador: PPGCI/ICI/UFBA, 2005. Disponível em <http:// www.cinform.ufba.br/vi_anais/docs/RodrigoMeirelles.pdf>. Acesso em: 26 set. 2005.

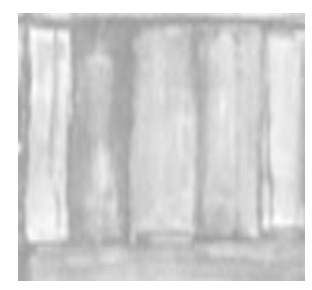

